\title{
Revealing the Power of Impact between Recruitment, Selection and Career Planning and Achieve Innovation then Entrepreneurship: A Study in U.A.E.
}

\author{
Dr. Mohamed Naser \\ Department of Management \\ Faculty of Business Administration \\ University of Sharjah \\ United Arab Emirates
}

\begin{abstract}
This article investigates the power of impact between some human resource management (HRM) functions (or policies) and achieve innovation then entrepreneurship. It provides pragmatic evidence of the abovementioned relationships through means of descriptive statistics and subsequently. It clarifies the effects over a regression analysis in the united arab emirates (UAE). The examination is made with statistical data collected from population of (10) pharmaceutical organizations which producing (manufacturing) drugs and medications out of (16) organizations were registered and licensed in this industry. Reference and data were used, carried out, and gathered between 2016 and 2019 respectively.
\end{abstract} (UAE).

Keywords: Innovation, Entrepreneurship, Human Resource Management (HRM), United Arab Emirates

\section{Introduction}

Human Resource progress was and still a priority for all those organizations which aspire to support economic development. By the increase in competition, organizations are forced to accelerate their rhythm of innovation and entrepreneurship. This can be made through different mechanisms: either by internal efforts in (HRM), research and development (R\&D) .... or through collaborative agreements which have become a strategy of knowledge sharing and transfer across organizations to access such external knowledge (Schilling, 2008).

The affiliation between (HRM) functions, innovation, and entrepreneurship was started from decades. As a whole, there is a preliminary linkage but historically (especially in the middle east) the literature didn't assess clearly the basic relationships yet (Wang \& Zang, 2005). Therefore, these exchangeable connections are still under progress in terms of impact and how each function will affect for potential of growth. So, large strands of economic literature (Wang, 2003); (Shrivastave \& Shaw, 2004) supported the positive role of (HRM) in fostering innovation. However, early innovation surveys starting with the annual innovation survey (Boston Consulting Group, 2006) suggested that although the importance of (HRM) is fully realized by most organizations and they continue to spend more and more on innovation and entrepreneurship activities. But many of these initiatives did not generate high profits or competitive advantages. Thereafter, recent articles indicated that, (HRM) might be a strong mediator for improving innovation and entrepreneurship (Moavenzadeh \& Griffiths, 2015). As a consequence, many regional and national governments, as well as international organizations, have sharply increased their investments in innovation-based policies (for example: Mikel Navarro et al., 2009). However, less have been investigated on the power of relationship between (HRM) functions and achieve innovation then entrepreneurship. Actually, explaining the role of some functions on organizations in-

* This article was submitted in January 2020, and accepted for publishing in April 2020.

(c) Arab Administrative Development Organization- League of Arab States, 2021, pp 313-330،

DOI: 10.21608/aja.2021.205204 
novation were underexposed (Kemp et al., 2003; Loof \& Heshmati, 2002; Van der Panne et al., 2003; Du Preez \& Louw, 2008; Daniel \& Sanz-Valle, 2005).

Therefore, the outline of article is as follow. After this introduction and background, in second part author reviews the literature on roles and functions of (HRM) from innovational and entrepreneurial perspective, dimensions of innovation and entrepreneurship and its contribution in the economic growth of (UAE). Part 3 presents research problem and restrictions. In part 4, it clarifies the main problem and sub questions, restrictions, research model, hypotheses, and methodology. Whereas part 5, provides the verification of relationship between some (HRM) functions and achieve innovation then entrepreneurship based on results of statistics analysis and hypotheses testing. Last part, presents the concluding remarks and managerial implications.

\section{HRM Roles and Functions in $21^{\text {st }}$ Century}

(HRM) is the segment of a business that recruits, trains, and develops an organization`s employees. It is the department of any organization which responsible for: staffing, training, compensation and benefits, career management, and performance appraisal. Human resource referred to as: (HR), human capital, casting (Disney term), or personnel (Mariotti \& Glackin, 2012). So, organizations cannot run without valuable sources called personnel. A pillar on which an organization stands is human resource management (Khanna, 2014).

To understand the modern roles and functions of (HRM), it is required first to start from innovational and entrepreneurial perspective. When organizations develop innovative outputs: introduce new products, improved processes, modern administrative practices; it need to recruit unique employees who are: flexible, risk takers, and accepting uncertainty and ambiguity (Chen \& Huang, 2007). So far, the resource that could design and sustain the template of innovation then entrepreneurship in organizations are (HRM).

The second role is to illuminate (HRM) participations in innovation and entrepreneurship by: encouraging of shaping the new culture, motivating the emergence of required leadership traits, and providing some tools to help overcome that fears (Bhatia, 2012).

On the other hand, the interventions argued by some economists (by asking experts and managers how they experienced successful improvement of innovativeness in their business life...etc.) aimed to discover organization's innovation capabilities, which helped to introduce new products, disseminate them successfully in different markets, through reactivate the (HRM) functions. However, outcome of previous interventions which oriented by achieving innovation and entrepreneurship depended on organization's strategies and resources. The arguments revealed that sustainable innovation requires a combination for long term between efforts and abilities (Kobe \& Goller, 2014). Within a sophisticated environment and more realization of challenges, (HRM) is supposed to play a new dominant role in promising organizations. So, (HRM) have to understand the organization's big picture and be always a customer driven. In order to achieve strategic objectives, (HRM) is not only be able to influence on performance, but also being a real strategic partner and change mentor toward implementing innovation and entrepreneurship (Rayen \& Jaya Ani, 2014).

As a result, (HRM) shouldn't just built a rigorous and standardized procedures, but it necessitates to generate and measure innovations in terms of (HRM) functions and then other departments functions. In order to be effective, there are no fixed functions for (HRM); functions must be consistent with the other parts inside and outside of any up to date organization. Depending on (Rayen \& Jaya Ani, Op Cite.; Akili, 2005) author suggests and adopts the most acknowledged and wide-ranging functions or polices of (HRM) as follow:

1- Recruitment and Selection. Current article

2- Research, Training, and Development.

3- Rewards, Benefits, and Recognition..

4- Career Planning.. Current article

5- Employees Engagement

6- Performance Management.. 
As stated earlier, the literature has few of articles that measured impacts (Naser, 2017) In this article, author embarks to nominate some functions as variables to measure (not just to confirm the relationship) exactly how it effects on perceived innovations (incremental and radical) and then entrepreneurship to plan for strategic objectives of organization. By looking back, the same mentioned functions were tested (by using diverse approaches) to develop performance (Khanna, Op Cite; Hameed \& Waheed, 2011; Adekola, 2011).

Many articles have shown that recruitment and selection together are not only the backbone of (HRM) as a management, but also for the entire organization. Therefore, the quality of human resource in any organization has heavily depends on the effectiveness of this function (Kepha, Mukulu, and Waititu, 2014; Gamage, 2014; Ekwoaba et al., 2015). Recruitment is a process of publicizing the vacancies or openings of any esteemed capacity (openings) in the most attractive and rightful manner with the sole objective of attracting maximum pool of eligible candidates for the position. It is also called as talent acquisition or procurement (Khanna, Op Cite). Whilst, the term selection simply is choosing a few from those who applied, some selection is: application banks, interview, business games, group discussion, and selection decision (Siddiqui, 2016). Accordingly, recruitment is identifying and encouraging prospective employees to apply for a job and selection is selecting right candidate from the pool of applicants among process as figure 1 shows:

\section{Recruitment \& Selection Process}

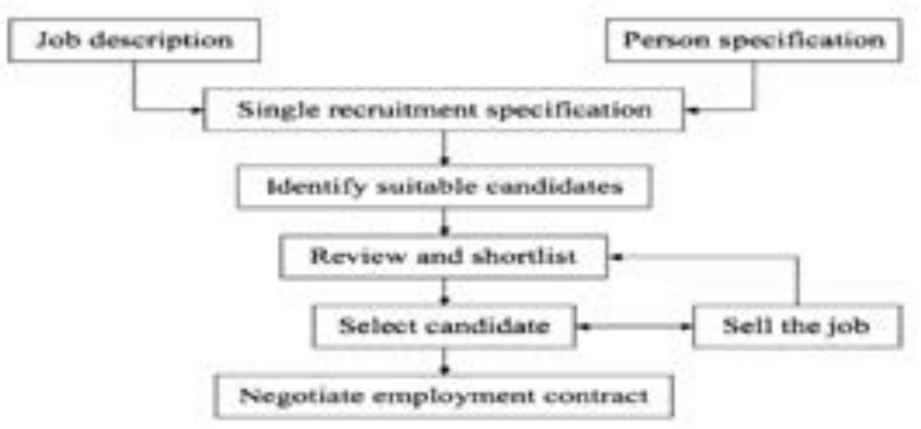

Figure (1) Recruitment \& Selection Process (Sudhamsetti \& Raju, 2014)

Career planning is an essential step in the process of helping individuals with disabilities to reach their employment goals. Career planning creates a road map for the employment process (Institute for Community Inclusion, 2012). Career planning helps organizations to deal with different changes proactively rather than reactively. Last but not least, career planning process can be expressed by the next figure.

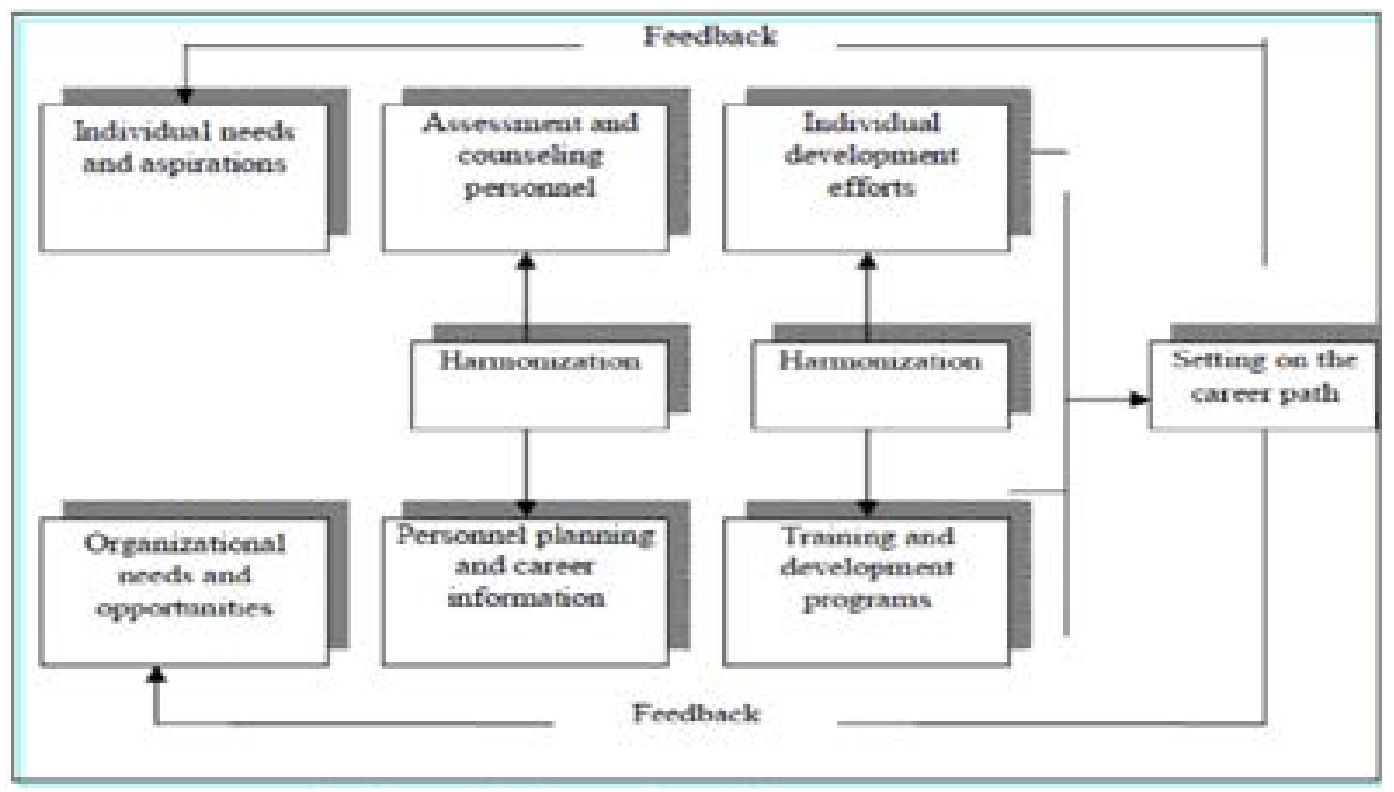

Figure (2) Career Planning Process (Antonio, 2010) 


\section{Dimensions of Innovation and Entrepreneurship:}

As the economies dramatically shifts and settles, recent changes in the world (especially in the Middle East) are being raised and required fundamental improvements in order to be familiar with updates in (HRM), innovation, and entrepreneurship.

Presently, we overcame the point which we can rely just on few brilliant or creative individuals. Innovation has to be on the organization-wide. Organizations need to figure out the design, process, and measurement methods for innovations so that it could produce and evaluate innovation after innovation. It is believed that, innovations are necessary for survival so it is not an event. It is a long-term process and commitment.

\section{First, What Do Creativity, Innovation and Entrepreneurship Stand For?}

Creativity is: the ability to generate wild ideas that have value and considered as the descent of innovation and entrepreneurship.

Innovation is: doing something significantly better or creating a stream of useful products or facilitating creative changes that will "waaw" people or ...etc. Whilst,

Entrepreneurship is: a multifaceted, complex, social and economic phenomenon or a mindset that can empower ordinary people to accomplish the extraordinary or the discipline of venture creation that transforms ideas into an organization that provides value to stakeholders or....etc. (Brynteson, 2013; Audretsch, 2002; Taulbert \& Schoeniger, 2010).

\section{Second, What Are the Importance of Creativity, Innovation and Entrepreneurship?}

Creativity studies, however, revealed that many of recent innovations we realize worldwide are not initiated by established organizations with large amount of talent and R\&D labs, but rather from dedicated, determined, and driven entrepreneurs who ideate an innovate big ideas to create new ventures that tap existing and new market (Nussbaum, 2013). Consistently, more information on the global competitiveness suggests that (USA) or Japan are not alone when it comes to recognizing the importance of innovation and entrepreneurship. For example, according to Colvin "A world values survey that asked people how important it is 'to think up new ideas and be creative...' placed the U.S. $10^{\text {th }}$, while other major economies like: Germany, France, and the U.K. ranked higher" (Colvin, 2013). Innovation is widely regarded as a driver for generating novel knowledge, economic growth, and jobs. Business author and speaker Tom Peters famously said "Innovate or die" (Peters, 2012). So, are we experiencing a large number of small innovations (Incrementalism)? Or are we experiencing a small number of large innovations (Radicalism). Therefore, how is it possible that we do not know for sure? Why not require organizations to measure their innovation competence?

The Information Technology and Innovation Foundation, and the Ewing Marion Kauffman Entrepreneurship Foundation released a report entitled the "Global Innovation Policy Index" ranking the capacities of 55 nations for economic growth in four tiers using 7 different criteria. The 7 areas then are weighted as follows: trade, science and R\&D, and digital policies at $17.5 \%$ for each, Intellectual property protection and domestic competition at 15\% each, Government procurement at 10\%, and lastly, High skill immigration at 7.5\% (Information Technology \& Innovation Foundation, 2012).

At its very core, entrepreneurship is about the creation of venture and value for multiple constituents by including (but not limited to): customers, employees, cities, regions, and even countries. For sure, the potential for economic growth and employment is substantially different depending on the business sector, 
the size, and the age of the entrepreneurship ecosystem that currently exists. Research show that entrepreneurship is the key to jobs creation: Startups account for $3 \%$ of (USA) employment but $20 \%$ of gross job creation (Porter \& Rivkin, 2012).

\section{Third, What Are Different Sources, Scales and Types of Innovations, and How Can Organization Design Strategy for Innovation and Entrepreneurship?}

Innovation sources could be board or narrow, and do not reside in any destination. Consequently, innovation is much boarder than simply product innovation. Innovation extends to incorporate all facets of business. There are five sources (also called voices) for defining the path of innovation, each has value and limitation as well. Hence, when thinking about innovation, it will be incomplete if we consider a single source. The following voices ultimately focus on human resources, next voices need to be empathic. The 5 sources of innovation are (Ulwick, 2012):

- Voice of the customer

- Voice of the job to be done

- Voice of open innovation

- Voice of the dreamer

- Voice of the product.

Since there are many scales, innovations have characteristics which are polymorphic. Organizing innovation into scales makes it easier to understand how to use multiple scales of innovation simultaneously. Practitioners and experts differentiated between key innovation scales as follow:

1- Administrative vs. technical. Based on the objective of innovation adoption;

2- Rational plan vs. communication web vs. disciplined problem solving. Based on the performance measures;

3- Competence enhancing vs. competence destroying. Based on innovation's effect on organization competencies;

4- Radical vs. incremental. Based on the extent of change to technology.

Among that, the last scale radical versus incremental innovation, has recently received much attention from researchers and practitioners who are interested in designing innovation strategies for instance (Lee, 2011; Nasser \& Abuzaid, 2014):

Based on the last scale (Radical-Incremental) the most suitable classification of innovations is as prescribed in the next:

- Product innovation: new registered product in the markets which organization presents;

- Process innovation: introduce the new notable ways or methods that products are created, transformed, and delivered;

- Position innovation: offer remarkable styles to offer products;

- Paradigm innovation: introduce significant new mental models and approaches of how organization differentiates (Francis \& Bessant, 2005).

Promised organizations used to define specific goals in order to achieve continued success, and accordingly select within what it innovates. This nomination would outline what it pays attention to and required strategies to follow. In short, the powerful combination of strategy and innovation creates a set of choices that enables any organization to win (Matthews \& Brueggemann, 2015). Here, designing innovation strategy brings new challenges and opportunities to light and opens toward the new. That is what exactly the entrepreneurs do, by screening new elements within a different frame and exploiting innovation opportunities for challenging objectives. At the moment, entrepreneurship can be understood as human 
characteristic which mixes: structure with passion, planning with vision, tools with the wisdom to use them, strategy with the energy to execute it, and judgment with the propensity to take risks. Definitely, this sets up the competitive dynamics which characterize innovation. It is the same of Schumpeter's conclusion when he wrote about the economic foundations of free organization and entrepreneurship, point that Drucker agrees and elaborates: "Innovation.... is the means by which the entrepreneur either creates new wealth producing resources or endows existing resources with enhanced potential for creating wealth" (Bessant \& Tidd, 2016; Owen, Bessant, and Heintz, 2013).

\section{Innovation and Entrepreneurship Mean a Long Commitment Trip:}

Built on (Stamm, 2008), innovation results from a series of stretchy, compound, and costly stages. It starts up with: recognition of opportunities for developments (discover needs), speculate and grow solutions (meaningful changes), and gain acceptance from all parties (collect benefits). Along the way, success, growth, and environment considerations push toward humongous changes in: plans, structures, tools, and sometimes the whole vision of organization. For that purpose, in the last decade there is a progress in interest: from steady structures and absolute measures to innovative activities (such as: R\&D expenditures and patents) to different type of interactions among actors within and beyond the boundaries of national system.

When reviewing the innovation process, part of the literature has understand the technological change process into three distinct phases, that is to say, the invention process (whereby new ideas are conceived), the innovation process (whereby those new ideas are developed into marketable products or processes), and the diffusion process (whereby the new products spread across the potential market) (Moreno \& Suriñach, 2014). Formerly, once organizations found themselves being unexpectedly disrupted by new entrants or losing share to existing competitors, it often made common mistakes by copying aircrafts that observed in the marketplace or read about in the previous cases. Later organizations seek to boost their innovation and entrepreneurship capabilities by undertaking one off brainstorming or ideation sessions to come up with their next progress. Instead, organizations need to: begin from inside and reveal the innovation barriers (which hindering), knock it down, reallocate existing resources and push toward chances of innovations and entrepreneurship that could be adopted and sustained (Kelley, 2010). By observing the entrepreneur's long life behavior, it reflects the following: endless commitment for very long time on believe, embark to confront challenges and abnormal risks regardless of results, and absolutely always abide by the next motto: serving is top priority.

\section{Innovation and Entrepreneurship are Mirrors of UAE Government}

Adopting innovation is crucial for (UAE)'s economic growth. In the arab world, (UAE) has the best understanding of what causes innovation and how to measure it. Designing clear standard metrics for measuring innovations let the country be able to differentiate between the real innovations, modifications, and adjustments. Subsequent to 2014, (UAE) has launched a National Innovation Strategy (NIS), and considered innovation and entrepreneurship in the top of government agenda under vision: (UAE) will become one of the most innovative countries in the globe within 7 years. (NIS) has defined the priority in 7 sectors: renewable and clean energy, water, transportation, technology, space, health care, and education. Moreover, (NIS) had committed innovation enabling environment through 4 areas: develop regulatory framework, offer services, establish technology infrastructure, and expand investment options (Moavenzadeh \& Griffiths, Op Cite.). On the other hand, regarding the efforts to shape innovation- based economy Minister of Economy, Sultan Al Mansouri stated that: "Knowledge and innovation are the basis of national economic growth, and implementation of the knowledge economy pillars is a strategic priority for the ministry to accelerate the transition to creativity and innovation based economy"(Al Mansouri, 2015). In a related context, on the $24^{\text {th }}$ of November 2015 Prime Minister of (UAE) launched the "Innovation Fund" with a value of 2 billion dirhams. It aims 
to finance: ideas, techniques, and products having commercial potential with intellectual property whether for individual or organizations (Editorial Team, 2016). Recently, the budgeted balance sheet of 2020 and for three years allocated $5 \%$ of the total expenditures on innovation and entrepreneurship activities.

As a result of persistent and dedication, (UAE) achieved gigantic strides toward reputation of the country as a global hub for innovation. Based on that vision, global innovation index indicated clearly (UAE) continued last four years to be the most innovative country in the arab world (Lanvin, Dutta and Wunsch-Vincent, 2016, 2017, 2018, 2019).

The article's endeavor is being able to: 1 - Analyze and address the innovation concept, type and level of emirate's pharmaceutical organizations. 2-Measure the exact power of impact for nominated functions which behind their growth. And 3- Decide effectively when, what and how to invest on each function within (HRM).

\section{Research Problem, Questions and Restrictions:}

The critical investigation here could be realized through article`s main problem: Till to any degree (HRM) within (UAE)'s pharmaceutical organizations is affecting to achieve innovation and then entrepreneurship. So far and whatever the nature of answer, it would include culture and environment considerations. Therefore, it is required to come back with the specific answers about following questions:

1- Are organizations aware enough about the consequences of innovations and entrepreneurship in order to achieve strategic goals?

2- Did (HRM) functions in organizations concentrate on changing the current culture toward innovation culture and did they have the openness to attaining it?.

Nevertheless, like any scientific effort there are some borders:

1- Some functions will be used as variables, because it is inaccurate mission to cover, test, and analyze all details of (HRM) in a single article. Likewise, same reason for perceived innovations, variables will be tested to achieve the famous scale of innovation as stated earlier: Radical-Incremental.

2- The mentioned variables will be examined in emirates pharmaceutical organizations for many considerations: A- Pharmaceutical organizations are ready by their own resources to react, invest, and use the output effectively. B- Globally, a record of implementing perceived innovations is long in pharmaceutical organizations (it is mainly built in). So, article (as a leading study in (UAE)) is expecting to find a suitable environment and common language to highlight on the quality of outputs.

3- Adopting innovation methodology is an up to date approach, so such kind of this examination will stimulate to perform the same for other managements, and that would be considered as a valuable addition to the scientific research and application as well.

\section{Research Model, Hypotheses and Methodology}

The article was conducted to ascertain the impact between variables in accepted sample of organizations. The ability to select a suitable method for any research is very important since it is a key to determining the reliability of research findings. As a summery, it necessitates defining, designing, and measuring the power of relationships through next parts.

\section{Research Model}

From now and in order to provide genuine answers, article need to define a research model (conceptual framework) to design the most appropriate hypotheses as well as testing different impacts. Figure 3 provides research model and different relationships. 


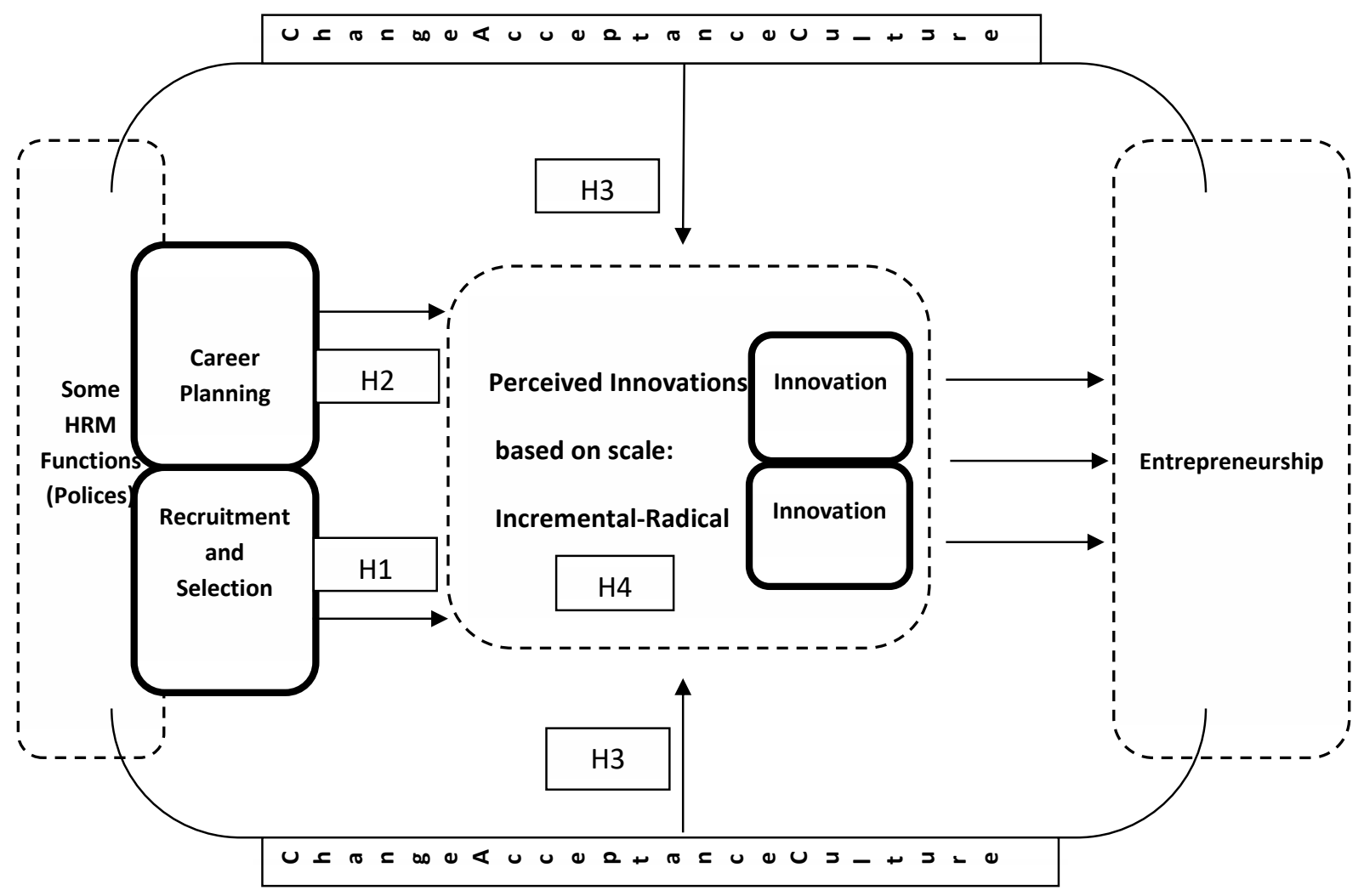

Figure (3) Research Model: Conceptual Framework

\section{Hypotheses}

A through understanding of the research, problem can be analyzed by applying hypotheses and testing it via collection of data and interpretation.

- H1: There is no significant linear relationship at $(\alpha \leq 0.05)$ between recruitment and selection and perceived innovations (radical and incremental) then entrepreneurship.

- $\quad$ H2: There is no significant linear relationship at $(\alpha \leq 0.05)$ between career planning and perceived innovations (radical and incremental) then entrepreneurship. $\mathrm{H} 1$ and $\mathrm{H} 2$ are derived from the next main hypothesis:

- H3: Human resource functions (recruitment \& selection and career planning) through change acceptance culture have statistically with significant at $(\alpha \leq 0.05)$ a good impact on perceived innovations (radical and incremental) then entrepreneurship.

- H4: There is no significant linear relationship at $(\alpha \leq 0.05)$ between incremental innovation and radical innovation within emirates pharmaceutical organizations.

The following section describes research methodology which used to assess hypothesized relationships and answer research questions.

\section{Methodology}

According to the article`s aim, the methodology was chosen to meet requirement of research that is capable to come back with convince results. For that goal, author used the descriptive methodology by reviewing literature which related to subject and disseminated a survey (questionnaire) which would be used to collect the required data to test the hypothesized relationships. The survey consists of two parts: 
- $\quad$ Part (A) covered the demographic variables, for instance organization age and size (number of employees), responses percentage from the study sample based on: gender, and years of experience.

- $\quad$ Part (B) covered the components of research model (independent and dependent variables). Answers of part (B) were built on Likert`s Scale, ranging from strongly disagree (1); disagree (2); moderately degree (3); i agree (4); and strongly agree (5). Some items in the questionnaire were adopted from (Darkoh, 2014;Nasser \& Abuzaid, Op Cite.)

\section{Power of Impact between Some (HRM) Functions and Innovation \& Then Entrepreneurship -Regression Analysis}

\section{Population, Sample \& Sampling Procedure, Data Collection Instrument and Data Analysis:}

The article was applied at emirate`s pharmaceutical organizations which producing (manufacturing) drugs and medications and is located in: Abu Dhabi, Dubai, Sharjah, and Ras Al-Khaimah. To get the sample of population, simple random sample technique was used to encompass primary data from (10) out of (16) organizations registered and worked within pharmaceutical industry. Statistically, as sample that constitutes $(62,5 \%)$ in the sector, it reflects a high creditability of results. The basic reasons behind nominating this industry are: it is the country where author resides; moreover, a research should be conducted within innovation driven sector to exert the hypothesized relationships clearly, and could afford (without any support) the lofty costs of innovation

All things being equal, the population should be a good representation of what really goes on regarding innovation and entrepreneurship, therefore the final sample size getting analyzed was (414) of all those duties which are related to: Innovation, (R\&D), and (HRM) within target organizations for accuracy purposes. Overall response rate was measured $(97,41 \%)$ of those who agreed to participate.

The statistical package for social sciences (SPSS) software was used here to analyze data. As literature deemed, (SPSS) is the most appropriate given its versatility and considering the nature of collected data.

\section{Findings and Discussion:}

1- Instrument's Reliability: to test the reliability of survey (questionnaire), Cronbach's alpha test was applied on variables and items as table 1 shows feedback.

The results (all Cronbach`s alpha scores are $>60 \%$ ), which means the manipulation for dependent and independent variables are reliable, stable, and effective (Sekaran, 2003; Sekaran \& Bougie, 2013).

Table (1)

Cronbach`s Alpha for all Variables

\begin{tabular}{ccc}
\hline Variables & $\begin{array}{c}\text { Number Cronbach`s } \\
\text { of Items }\end{array}$ \\
\hline Alpha Value \\
\hline Recruitment and Selection & 10 & 0,71 \\
\hline Career Planning & 9 & 0,70 \\
\hline Change Organizational Culture & 10 & 0,74 \\
\hline $\begin{array}{c}\text { Concepts\& Importance of } \\
\text { Innovation and Entrepreneurship }\end{array}$ & 6 & 0,86 \\
\hline Radical Innovation & 5 & 0,69 \\
\hline Incremental Innovation & 5 & 0,71 \\
\hline
\end{tabular}

2- Descriptive Statistics: The characteristics of study population and sample are prescribed in the tables $(2,3,4$, and 5) accordingly. Statistical methods will be applied to get meaningful information.

It is clear from the ages that, (30\%) of sample are more than 20 years old. Emirates pharmaceutical organizations showed a high level of stability and its flexibility to adapt with the changes of industry and in different markets.

Table (2)

Descriptive Statistics-

Organization Age

\begin{tabular}{|c|c|c|}
\hline Organiza & tion Age & anizations \\
\hline & $<10$ & 4 \\
\hline $\mathrm{N}=10$ & $10-20$ & 3 \\
\hline (in years) & $21-30$ & 1 \\
\hline & $31-40$ & 2 \\
\hline
\end{tabular}


Based on the emirate's classifications, only one organization is considered as a small business, while (70\%) of sample are medium businesses, whereas (20\%) are large organizations and have more than 500 employees.

Based on sample feedback, (72\%) of the respondents are male and the rest (28\%) are female. That means, males are constituting the dominant part of (R\&D), innovation and entrepreneurship jobs in the pharmaceutical organizations.

It is clear that, over $45 \%$ of the respondents have less than 10 years of experience. Expectedly, or-

Table (4)

Descriptive statistics- Gender Gender Frequency Percentage

\begin{tabular}{ccc}
\hline Male & 298 & 72 \\
\hline Female & 116 & 28 \\
\hline Total & 414 & $100 \%$ \\
\hline
\end{tabular}
ganizations owners provided more attention to the fresh bloods to take control over innovative and entrepreneurial processes.

3- Data Presentation: In order to test the hypotheses, article need to use descriptive statistic measures to show the average distribution of sample. Means and standard deviations were used. Data can be discussed as specified below.

The table indicates that, all values of mean were positive and upper than supposed ones (3). The highest answer recorded for incremental innovation $(4,06)$. At the same time, results are lower than 1 in standard deviations and that provides a high level of consistency toward variables of study except the variable: concepts and importance of innovation and entrepreneurship $(1,026)$; it means a clear variance in the respondents toward this variable.

4- Hypotheses Testing: to scrutinize the hypothesized relationships, it is common to check this part of any research which is dedicated to testing the validity of hypotheses. Author suggests to classify the correlation between variables as follow (Al Obaid, 2004):

$\left[0 \leq\left|r_{x y}\right| \leq 0.3\right]$ Poor $\left[0.3 \leq\left|r_{x y}\right| \leq 0.6\right]$ Moderate

$\left[0.6 \leq\left|r_{x y}\right| \leq 0.8\right]$ Good $\left[0.8 \leq\left|r_{x y}\right| \leq 1\right]$ Strong.

Subsequently, regression analysis (Simple, Multiple, and One-way analysis of variance (One-Way ANOVA) ) is inevitability depending on the Model and hypotheses.

\section{A- First Test Describes the Impact of Recruitment \& Selection on Perceived Innovations.}

As provided in tables $(7,8$, and 9$)$.

As shown in the above, results indicate that the value of $(R)$ square $(0,238)$. It means recruitment and selection explains $(23,8 \%)$ from the variance in the dependent variable (perceived innovations).

As prescribed in the table results indicate that the value of $(F)$ is $(128,751)$ with significance value is much less than
Means and standard deviations

\begin{tabular}{ccc}
\hline Variables & Mean & $\begin{array}{c}\text { Standard } \\
\text { Deviation }\end{array}$ \\
\hline Recruitment and Selection & 3,63 &, 771 \\
\hline Career Planning & 3,38 &, 881 \\
\hline Change Organizational Culture & 3,45 &, 879 \\
\hline $\begin{array}{c}\text { Concepts \& Importance of In- } \\
\text { novation and Entrepreneurship }\end{array}$ & 3,25 & 1,026 \\
\hline Radical Innovation & 3,53 &, 747 \\
\hline Incremental Innovation & 4,06 &, 658 \\
\hline
\end{tabular}

Table (6)
Table (3)

Descriptive statistics- No. of Employees

Organization Size \# Organizations

\begin{tabular}{ccc}
$N=10$ & $<50$ & 1 \\
\cline { 2 - 3 } Employees & $51-250$ & 4 \\
\cline { 2 - 3 } (No. of & $251-450$ & 3 \\
\cline { 2 - 3 } employees) & $451<$ & 2 \\
\hline
\end{tabular}

Table (5)

Descriptive statistics- Years of experience

\begin{tabular}{ccc}
\hline $\begin{array}{c}\text { Years of } \\
\text { Experience }\end{array}$ & Frequency & Percentage \\
\hline$<5$ & 78 & 18,84 \\
\hline $5-10$ & 112 & 27,05 \\
\hline $11-15$ & 62 & 14,98 \\
\hline $16-20$ & 87 & 21,01 \\
\hline $20<$ & 75 & 18,12 \\
\hline Total & 414 & $100 \%$ \\
\hline
\end{tabular}


$(0,05),(P=0,000)$, it means the variation explained by this model is not due to chance, so the results of test are suitable and acceptable.

As shown in last table, results of regression analysis indicate that recruitment $\&$ selection outcome effects on organization innovations. Values of beta and t-tests show that recruitment $\&$ selection have a positive and moderate correlation $(0,448)$ on perceived organization innovations. Facts are against H1. So:

Based on the above tables, author rejects null hypothesis $\mathrm{H} 1$ and accepts alternative hypothesis which stated: There is significant linear relationship at $(\alpha \leq 0.05)$ between recruitment and selection and perceived innovations (radical and incremental) then entrepreneurship.

B- Second Regression Test Describes the Relationship between Career Planning and Perceived Innovations. Following tables (10,11 and 12)

propose the generated data.

Regarding the prior tables, regression analysis provides: $(F)=(28,362),(P=0,000)$ it means the variation explained by this test is significant. However, $(R)$ is $(0,254)$ which indicate to positive and poor correlation between career planning and perceived innovations. $(R)$ square $(0,064)$ meaning that, career planning could explain only $(6,4 \%)$ of the variance in perceiving innovations (radical and incremental) in the emirate's pharmaceutical organizations. All results partially reject $\mathrm{H} 2$, So:

Based on the results from earlier tables, author rejects $\mathrm{H} 2$ and accept fairly the alternative hypothesis, which stated: There is significant linear relationship at $(\alpha \leq 0.05)$ between career planning and perceived innovations (radical and incremental) then entrepreneurship. By comparing the power of impact between career planning and recruitment and selection, Author can decide that career planning impact's is relatively lower in explaining the variation of perceived innovations (radical and incremental).

C- Third Test Describes the Relationship between Some (HRM) Functions (Recruitment and Selection, and Career Planning) Simultaneously and Perceived Innovations through tables (13, 14, and 15).

As shown in the table, $(R)(0,624)$ meaning that there is a good and positive correlation between re-
Table (8)

ANOVA analysis ${ }^{b}$

\begin{tabular}{cccccc}
\hline Model & $\begin{array}{c}\text { Sum of } \\
\text { Squares }\end{array}$ & df & $\begin{array}{c}\text { Mean } \\
\text { Square }\end{array}$ & F & Sig. \\
\hline Regression & 100,107 & 1 & 100,107 & 128,751 & $0,000^{\mathrm{a}}$ \\
\hline Residual & 320,339 & 412 & 0,778 & & \\
\hline Total & 420,446 & 413 & & & \\
\hline
\end{tabular}

Predictors: (Constant), Recruitment \& Selection

b. Dependent Variable: Perceived Innovations.

Table (9)

Coefficients ${ }^{\text {a }}$

\begin{tabular}{|c|c|c|c|c|}
\hline \multirow{3}{*}{$\begin{array}{c}\text { Model } \\
\text { B }\end{array}$} & \multicolumn{2}{|c|}{ Unstandardized Standardized } & \multirow{3}{*}{$\mathbf{t}$} & \multirow{3}{*}{ Sig. } \\
\hline & & Coefficient & & \\
\hline & \multicolumn{2}{|l|}{ Std. Error Beta } & & \\
\hline (Constant) & 2,151 & & 19,757 & 0,000 \\
\hline Outcomes & 0,425 & 0,488 & 11,347 & 0,000 \\
\hline
\end{tabular}

Dependent Variable: Perceived Innovations.

Table (10)

The Model Summery

\begin{tabular}{ccccc}
\hline Model & $\mathbf{R}$ & $\begin{array}{c}\mathbf{R} \\
\text { square }\end{array}$ & $\begin{array}{c}\text { Adjusted } \\
\text { R square }\end{array}$ & $\begin{array}{c}\text { Std. Error of } \\
\text { The Estimate }\end{array}$ \\
\hline 1 & $0,254^{\mathrm{a}}$ & 0,064 & 0,062 & 0,97712 \\
\hline Predictors: (Constant), Career Planning
\end{tabular}

Table (11)

ANOVA Analysis ${ }^{b}$

\begin{tabular}{|c|c|c|c|c|c|c|}
\hline & Model & $\begin{array}{l}\text { Sum of } \\
\text { Squares }\end{array}$ & df & $\begin{array}{l}\text { Mean } \\
\text { Square }\end{array}$ & $F$ & Sig. \\
\hline & Regression & 27,079 & 1 & 27,079 & 28,362 & $0,000^{a}$ \\
\hline \multirow[t]{2}{*}{1} & Residual & 393,367 & 412 & 0,955 & & \\
\hline & Total & 420,446 & 413 & & & \\
\hline
\end{tabular}

Predictors: (Constant), Career Planning

a. Dependent Variable: Perceived Innovations.

Table (12)

Coefficients $^{\text {a }}$

\begin{tabular}{|c|c|c|c|c|}
\hline $\begin{array}{c}\text { Model } \\
\text { B }\end{array}$ & $\begin{array}{l}\text { Unstandard- } \\
\text { ized Coefficient } \\
\text { Std. Error Beta }\end{array}$ & $\begin{array}{c}\text { Standardized } \\
\text { Coefficient }\end{array}$ & $\mathbf{t}$ & Sig. \\
\hline (Constant) & $2,488 \quad 0,157$ & & 15,851 & 0,000 \\
\hline Outcomes & $0,241 \quad 0,045$ & 0,254 & 5,326 & 0,000 \\
\hline
\end{tabular}

Dependent Variable: Perceived Innovations.

Table (13)

The Model Summery

\begin{tabular}{ccccc}
\hline Model & $\mathbf{R}$ & $\begin{array}{c}\mathbf{R} \\
\text { square }\end{array}$ & $\begin{array}{c}\text { Adjusted } \\
\mathbf{R} \text { square }\end{array}$ & $\begin{array}{c}\text { Std. Error of } \\
\text { The Estimate }\end{array}$ \\
\hline 1 & $0,624^{\mathrm{a}}$ & 0,389 & 0,388 & 0,78937 \\
\hline Predictors: (Constant), Recruitment and Selection, Career Planning
\end{tabular}


cruitment \& selection, and career planning and perceived innovations. Besides, results revealed that $(R)$ square $(0,389)$, it means the tested (HRM) functions explain $(38,9 \%)$ from the variance in perceived innovations.

Based on data, results indicate that, value of $(F)$ is $(262,759)$ with significant $(0,000)$ which is lower than the specified value $(0,05)$ so this model is suitable and acceptable.

The results of regression analysis indicate that (HRM) functions (recruitment and selection, and career planning) effect on perceived organization innovations. The values of beta and t-tests show that (HRM) functions (recruitment and selection, and career planning) through change acceptance culture have a positive and good impact on perceived organization innovations.

Based on the results author accepts H3: Human resource functions (recruitment \& selection and career planning) through change acceptance culture have statistically with significant at $(\alpha \leq 0.05)$ a good impact on perceived innovations (radical and incremental) then entrepreneurship.

D- Fourth for Explaining the Relationship between the Two Types of Innovation, results of test are shown in table (16).

The above table describes that $(F)$ $(10,396)$ and its significance value $(0,000)$. (R) $(0,54)$ which indicates a positive and moderate correlation between incremental innovation and radical innovation. $(R)$ Square $(0,412)$ illuminates that, incremental innovation could explain (41,2\%) of the variation in radical innovation of emirate 's pharmaceutical organizations. With the rest of explanation (58.8\%), this result supports previous feedback that study sample are sharing a common view toward innovation as a radical change.

Based on the results author rejects $\mathrm{H} 4$, and accepts alternative hypothesis which stated: There is significant linear relationship at $(\alpha \leq 0.05)$ between incremental innovation and radical innovation within emirates pharmaceutical organizations. In other words, incremental innovation at emirates pharmaceutical organizations has a moderate and positive impact with statistically significant at $(\alpha \leq 0.05)$ on radical innovation.

\section{Conclusions}

Briefly, following results obtained from analysis which conducted by questionnaire:

- During the survey, participants confirmed that career planning practices assist them to improve their performance, but freedom of making decisions was focused with few....

- According to results, recruitment and selection function have significant value of respondent`s innovations and then entrepreneurship. Recruitment and selection function are able to explain about 
$(23,8 \%)$ from the variance in the dependent variable (perceived innovations).

- Career planning function has a positive, but with a very low effect $(6,4 \%)$ on perceived innovations compared to the recruitment and selection.

- The collective impact for same functions which were tested separately indicated that: Recruitment and selection and career planning through change acceptance culture have a positive and good effect $(62,4 \%)$ on perceived innovations (radical and incremental), and are able together to interpret about $(38,9 \%)$ from the variance in the perceived innovations. But on the other side, by considering the entire functions of (HRM), results and power of impacts definitely would be changed.

- The answers and tests revealed that, emirates pharmaceutical organizations have high level of awareness about the consequences of innovations and entrepreneurship in order to achieve strategic goals.

- The field study showed that, change organizational culture has a visible part in accepting concepts and importance of innovation and then entrepreneurship in the emirate's pharmaceutical organizations.

- In addition, results indicated that there is a moderate impact of incremental innovation with statistically significant at $(\alpha \leq 0.05)$ on radical innovation.

- On the basis of analysis, it might be concluded that the nominated functions have clear contribution to achieve innovation and then entrepreneurship.

- Last but not least, other articles in the same field such as: (Tan \& Nasurdin, 2011; Sreeja, 2018) have equally agree and sustain results of the article.

\section{Managerial Implications}

In view of the above conclusions which were drawn from tests, the following points must be well noted:

- First- apart from conclusions, the practice exposed that emirates manufacturing drugs and medications organizations did not have a unified policy toward innovations; each organization has its own approach. Thus, the mentioned (HRM) functions through change acceptance culture disclosed different effects of adoption innovations and then.

- Second- this article is primarily focused on (HRM) and innovations then entrepreneurship in pharmaceutical organizations. Undeniably, it supports other articles but in different sectors and destinations as well.

- Third- although article has got specific consequences to achieve innovation and entrepreneurship, but it didn 't provide answer concerning whether these conclusions have direct and significant impacts upon other managerial functions (for instance: production) which working within pharmaceutical organizations.

- Forth- (HRM) functions have positive but different impacts toward innovations and this result can be used promptly to reallocate resources in pharmaceutical organizations. 


\section{References:}

Akili, Omar Wasfi. (2005). Contemporary Human Resource Management. Dar Wael for Publishing Inc., Amman- Jordan, ISBN: 9957-11-498-0.

Adekola, Bola. (2011). “Career Planning and Career Management as Correlates for Career Development and Job Satisfaction: A Case Study of Nigerian Bank Employees", Australian Journal of Business and Management Research, Vol. 1, No. 2, pp. 100-112.

- Al Mansouri, Sultan Saeed. (2015). The Ministry of Economy is Committed to Shaping a Creative and Innovation-based Business Environment, UAE Economy, Ministry of Economy, Issue. 20, December, pp. 31-35.

- $\quad$ Al Obaid, Abdurrahman Ahmed. (2004). Principles of Managerial Forecasting. King Saud University Press, Riyadh- Kingdom of Saudi Arabia, pp. 60.

Antonio, Eliza. (2010). “Career Planning Process and its Role in Human Resource Development, Economics", Annals of the University of Petroşani-Romania, Vol. 10, No. 2, pp. 13-22.

Audretsch, David B. (2002). "The Dynamic Role of Small Firms: Evidence from the USA.", Small Business Economics, Vol. 18, No. 1, pp. 13-40.

- $\quad$ Bessant, John and Tidd Joe. (2016). Innovation and Entrepreneurship. $5^{\text {th }}$ Edition, John Wiley \& Sons Ltd., Chichester, West Sussex- UK., pp. 10-11.

Bhatia, Arun and Rashmi. (2012). "Marketing and HR Innovation in Business", International Journal of Innovations in Business, Vol. 1, No. 1, pp. 12-39.

- Boston Consulting Group. (2006). Innovation 2006, Online: https://web-assets.bcg. com/13/93/70656b8647538e00f75b390bb7a7/2006-innovation-report.pdf.

- $\quad$ Brynteson, Richard. (2013). Innovation at Work. American Management Association (AMACOM), New York- USA, xi-xiii.

Chen, Chung and Huang Jing. (2007). "How Organizational Climate and Structure Affect Knowledge Management: The Social Interaction Perspective", International Journal of Information Management, Vol. 27, No. 2, pp. 104-112.

- Colvin, Geoff. (2013). A Mighty Culture of Innovation cannot be Taken for Granted, Fortune. com, September 16. Online: http://www.Fortune.com/2013/08/29/a-mighty-culture-of-innovation-cannot-be-taken-for-granted/.

- Daniel Jiménez-Jiménez, and Sanz-Valle Raquel, 2005, Innovation and Human Resource Management Fit: An Empirical Study, International Journal of Manpower, Vol. 26, No. 4, 364-381.

- Darkoh, Mavis Adu. (2014). Employee Recruitment and Selection Practices in the Construction Industry in Ashanti Region, A Thesis Submitted to the Department of Managerial Science, University of Science and Technology, xiv - xvii.

- Du Preez, N. D. and Louw, L. (2008). "A Framework for Managing the Innovation Process", Portland International Conference for Management of Engineering \& Technology (PICMET 2008), 27-31 July. Cape Town- South Africa, pp. 546-558.

- Editorial Team. (2016). Innovation and Scientific Research Carry UAE to Knowledge Economy, UAE Economy, Ministry of Economy, Issue 24, December, pp. 26-28.

- Ekwoaba, Joy O.; Ikeije Ugochukwu U. and Ufoma Ndubuisi. (2015). “The Impact of Recruitment and Selection Criteria on Organizational Performance", Global Journal of Human Resource Management, Vol. 3, No. 2, pp. 22-33.

- Francis, Dave and Bessant John. (2005). "Targeting Innovation and Implications for Capability Development", Technovation, Vol. 25, No. 3, pp. 171-183.

- Gamage, Aruna. (2014). "Recruitment and Selection Practices in Manufacturing SMEs in Japan: An Analysis of the Link with Business Performance", Ruhuna Journal of Management and Finance, Vol. 1, No. 1, pp. 37-52. 
Hameed Abdul and Waheed Aamer. (2011). “Employee Development and its Affect on Employee Performance a Conceptual Framework", International Journal of Business and Social Science, Vol. 2, No. 13, pp. 224-229.

- Information Technology and Innovation Foundation. (2012). Global Innovation Policy Index Report, Kauffman Foundation, March 17, Online: http://www.Kauffman.org/what-we-do/research/2012/03/the-global-innovation-policy-index \& http://www.itif.org/publications/global-innovation-policy-index.

- Institute for Community Inclusion. (2012). The Career Planning Process: A Guide to Person Centered Career Planning in Connecticut. University of Massachusetts, Boston- USA, pp. 2-3. Kelley, Braden. (2010). Stoking Your Innovation Bonfire. John Wiley \& Sons Inc., New Jersey- USA., pp. 1-2.

- $\quad$ Kemp, RGM; Folkeringa, M.; De Jong JPJ. and Wubben EFM. (2003). Innovation and Firm Performance. Research Report H200207, ISBN: 90-371-0875-X.

- Kepha, Ombui; Mukulu Elegwa and Waititu Gichuhi A. (2014). "The Influence of Recruitment and Selection on the Performance of Employees in Research Institutes in Kenya", International Journal of Science and Research (IJSR), Vol. 3, No. 5, pp. 132-138.

- Khanna, Pooja. (2014). "Recruitment and Selection of the Hour for Organizational Success", International Journal of Research in Management and Technology, ISSN: 2249-9563, Vol. 4, No. 3, pp. 149-155.

Kobe, Carmen and Goller Ina. (2014). Four Approaches to Fostering Companies' Innovation Capability, Innovationmanagement.se. http://www.innovationmanagement.se/2011/06/29/ four-approaches-to-fostering-companies-innovation-capability/.

- Lanvin, Bruno. Dutta Soumitra and Wunsch-Vincent Sacha. (2016, 2017, 2018, 2019). The Global Innovation Index: $\mathbf{9}^{\text {th }}, 10^{\text {th }}, 11^{\text {th }}, 12^{\text {th }}$ Editions, Suggested Citation: Cornell University, INSEAD, and WIPO, Geneva- Switzerland, Online: http://www.globalinnovationindex.org.

- $\quad$ Lee, Jung Young. (2011). "Incremental and Radical Innovation: The Impacts of Human, Structural, Social and Relational Capital Elements", A Dissertation Submitted to Michigan State University in Partial Fulfillment of the Requirements for the Degree of Doctor of Philosophy in Operations and Sourcing Management, pp. 16-20.

- Loof, Hans and Heshmati Almas. (2002). “On the Relationship between Innovation and Performance: sensitivity Analysis, Royal Institute of Technology", Industrial Economics and Management. The United Nation University- UNU/WIDER.

- Mariotti, Steve and Glackin Caroline. (2012). Entrepreneurship and Small Business Management. Pearson Education Inc., Upper Saddle River, New Jersey-USA, 530-538.

- Matthews, Charles H. and Brueggemann Ralph. (2015). Innovation and Entrepreneurship. Routledge Press, New York- USA., p. 73.

- Mikel, Navarro J. J.; Bilbao Osorio B. and Aguado R. (2009). "Environment and Planning", Government and Policy Journal, Vol. 27, pp. 815-840.

Moavenzadeh, Fred and Griffiths Steve. (2015). "Research and Innovation", Masdar Institute and MIT Collaborative Research Conference. 13 April. Abu Dhabi- U.A.E.

- Moreno, Rosina and Suriñach Jordi. (2014). Innovation Adoption and Productivity Growth: Evidence for Europe, AQR Research Group-IREA. Department of Econometrics, Vol. 13, University of Barcelona- Spain, 5-6.

- Naser, Mohamed. (2017). The Link between Some HRM Functions and Importance of Implementing Innovations (Radical-Incremental) For Being an Entrepreneurship, Innovation Arabia 10 Conference, Dubai- UAE. 
Nasser, Ahmad and Abuzaid Ahmad. (2014). "The Impact of Strategic Alliance Partner Characteristics on Firms Innovation: Evidence from Jordan", International Journal of Business and Management, Vol. 9, No. 3, pp. 77-87.

- $\quad$ Nussbaum, Bruce. (2013). Creative Intelligence. Harper Business Press, New York- USA., p. 37.

- Owen, Richard; Bessant John and Heintz Maggy. (2013). Responsible Innovation: Managing the Responsible Emergence of Science and Innovation in Society. John Wiley \& Sons Ltd., West Sussex- UK., Printed in Malaysia, pp. 5-22.

- Peters, Tom. (2012). Innovate or Die: The Innovation 121 A Menu of (Essential) Innovation Tactics, Tom Peter's blog, http://tompeters.com/blogs/freestuff/uploads/Innov_tactics121_Appends011309. pdf. Accessed: June 17, 2016.

- Porter, Michael and Rivkin Jan. (2012). "What Business Should Do to Restore Competitiveness?", Fortune, October 15, Online: https://fortune.com/2012/10/15/what-business-should-do-to-restore-competitiveness/

- $\quad$ Rayen, Lourdes and Jaya Ani J. (2014). Creativity and Innovation. Discovery Publishing House PVT Ltd., New Delhi- India, pp. 187-203.

- Schilling, Melissa. (2008). "Understanding the Alliance Data", Strategic Management Journal, Vol. 30, No. 3, pp. 233-260.

- $\quad$ Sekaran, Uma. (2003). Research Method for Business: A Skill Building Approach. $4^{\text {th }}$ Ed., John Wiley \& Sons Inc., New Jersey- USA.

- Sekaran, Uma and Bougie R. (2013). Research Method for Business: A Skill Building Approach. $6^{\text {th }}$ Ed. GAO, Government Auditing Standards.

- Shrivastave, Samir and Shaw James. (2004). "Liberating HR through Technology", Human Resource Management, Vol. 42, No. 3, pp. 201-220.

- Siddiqui, Neha Nazneen. (2016). "Recruitment and Selection Process of a Leading Telecom Company", American Journal of Management Science and Engineering, Vol. 1, No. 2, pp. 54-60.

- Sreeja, K. (2018). "HRM and Organizational Innovation: A Literature Review”, Journal of Business Management, Vol. 4, No. 2, pp. 28-31

- $\quad$ Stamm, Battina Von. (2008). Managing Innovation, Design and Creativity. $2^{\text {nd }}$ Ed., John Wiley \& Sons Ltd., Chichester, West Sussex- UK., 6.

- $\quad$ Sudhamsetti, Naveen and Raju D. N. M. (2014). “A Study on Recruitment \& Selection Process with Reference to Three Different Industries", Journal of Business and Management, Vol. 15, No. 5, pp. 60-67.

- Tan, Cheng L. and Nasurdin Aizzat M. (2011). “Human Resource Management- Practice and Organizational Innovation-: Assessing the Mediating Role of Knowledge Management Effectiveness", The Electronic Journal of Knowledge Management, Vol. 9, No. 2, pp. 155-167.

- Taulbert Clifton and Schoeniger Gary, 2010, Who Owns the Ice House? 8 Lessons from an Unlikely Entrepreneur, OH: ELI Press.

- Ulwick, Tony. (2012). Innovation Starts by Targeting the Right Customer. December 18, http:// strategyn.com/2012/12/18/who-is-your-customer/

- Van der Panne, G.; Van beers, C. and Kleinknecht A. (2003). "Success and Failure of Innovation: A Review of the Literature", International Journal of Innovation Management, Vol. 7, No. 3, pp. 309-338.

- Wang, Zhong Ming and Zang, Zhi. (2005). "Strategic Human Resources, Innovation and Entrepreneurship Fit: A Cross-Regional Comparative Model", International Journal of Manpower, Vol. 26, No. 6, pp. 544-559.

Wang, Zhong Ming. (2003). "Chinese Models of Entrepreneurship and Strategic Human Resource", The International Conference on Managing HR in the high growth firms, 14-15 February, Columbus-Ohio. 


\section{Appendix (1)}

\section{Questionnaire}

Please fill both parts completely by ranging from strongly disagree (1); disagree (2); moderately degree (3); I agree (4); and strongly agree (5).

\section{Part A}

\section{Organization Data}

- Name of the organization:

- Industry Type:

- Organization Age:

- No. of employees:

\section{Personal Data}

- Gender:

- Total professional experience:

- Current Position:

- Email:

- Postal Address

\section{Part B}

\section{Recruitment and Selection}

- Our organization have a clear policy for recruitment and selection

$\begin{array}{lllll}1 & 2 & 3 & 4 & 5\end{array}$

- The recruitment and selection practices affected on employee performance

$\begin{array}{lllll}1 & 2 & 3 & 4 & 5\end{array}$

- Competency level on the part of employee is dominant in recruitment and selection

$\begin{array}{lllll}1 & 2 & 3 & 4 & 5\end{array}$

- Lack of experience is one of challenges construction organization encountered

$\begin{array}{lllll}1 & 2 & 3 & 4 & 5\end{array}$

- Cost of recruitment and selection of employees sometimes hinder the developments

$\begin{array}{lllll}1 & 2 & 3 & 4 & 5\end{array}$

- There are formal evaluation tools to assess effectiveness of recruitment and selection

$\begin{array}{lllll}1 & 2 & 3 & 4 & 5\end{array}$

- The employer employee relationship could be considered without boundaries

$\begin{array}{lllll}1 & 2 & 3 & 4 & 5\end{array}$

- Involvement of Agents for recruitment and selection is absent

$\begin{array}{lllll}1 & 2 & 3 & 4 & 5\end{array}$

- Effective job analysis and selection methods are used to predict future needs

$\begin{array}{lllll}1 & 2 & 3 & 4 & 5\end{array}$

- Fresh Graduates from universities have comparable opportunities of recruitment

\section{Career Planning}

- Employees at each level in our organization have clear career hierarchy

$\begin{array}{lllll}1 & 2 & 3 & 4 & 5\end{array}$

- Employees in our organization are aware about their career progresses

$\begin{array}{lllll}1 & 2 & 3 & 4 & 5\end{array}$

- Organizational and individual growth needs are aligned in this organization

$\begin{array}{lllll}1 & 2 & 3 & 4 & 5\end{array}$

- Our organization takes career planning and succession planning critically

$\begin{array}{lllll}1 & 2 & 3 & 4 & 5\end{array}$

- At our organization internal hiring is preferred over external

$\begin{array}{lllll}1 & 2 & 3 & 4 & 5\end{array}$

- New employees always get inspired by our career planning and development system

$\begin{array}{lllll}1 & 2 & 3 & 4 & 5\end{array}$

- Organization is helping me enhance skills needed for future progress

$\begin{array}{lllll}1 & 2 & 3 & 4 & 5\end{array}$

- Our organization provides opportunities to update skills needed to meet career aims

$\begin{array}{lllll}1 & 2 & 3 & 4 & 5\end{array}$

- Employees get career guidance from their supervisor without any delay

$\begin{array}{lllll}1 & 2 & 3 & 4 & 5\end{array}$ 


\section{Change Organizational Culture}

- Individual performance is emphasized as an important goal, achievements in increasing performance are rewarded.

$\begin{array}{lllll}1 & 2 & 3 & 4 & 5\end{array}$

- Ideas are welcomed from any level in the organization everyone's views are taken into account before important decisions are made.

- Organization tries as soon as possible new ideas, even if it is not guaranteed that it will work.

$\begin{array}{lllll}1 & 2 & 3 & 4 & 5\end{array}$

- Decisions are made promptly and on the basis of the facts, not self-interest.

$\begin{array}{lllll}1 & 2 & 3 & 4 & 5\end{array}$

- Managers take responsibility for their decisions and are not penalized if results are not as they expected. $\begin{array}{lllll}1 & 2 & 3 & 4 & 5\end{array}$

- Professionalism matter is frequently discussed and regarded as an important asset

$\begin{array}{lllll}1 & 2 & 3 & 4 & 5\end{array}$

- Time and money are committed to exploring new ideas.

$\begin{array}{lllll}1 & 2 & 3 & 4 & 5\end{array}$

- Employees feel that their views are valuable, will be considered carefully and acted on accordingly if it deserves.

$\begin{array}{lllll}1 & 2 & 3 & 4 & 5\end{array}$

- Employees say what they really think and information on future plans...etc. is readily accessible

$\begin{array}{lllll}1 & 2 & 3 & 4 & 5\end{array}$

- Sometimes it is required an extra effort to realize customers' needs and business chances

$\begin{array}{lllll}1 & 2 & 3 & 4 & 5\end{array}$

\section{Concepts and Importance of Innovation and Entrepreneurship}

- Innovation and Entrepreneurship involved fundamentally new concepts for our organization.

$\begin{array}{lllll}1 & 2 & 3 & 4 & 5\end{array}$

- Organization introduced innovation by making simple adjustments for existing technology.

$\begin{array}{lllll}1 & 2 & 3 & 4 & 5\end{array}$

- Innovation requisite new human skills but organization did not possess yet.

$\begin{array}{lllll}1 & 2 & 3 & 4 & 5\end{array}$

- Innovation required organization to adopt different methods and procedures.

$\begin{array}{lllll}1 & 2 & 3 & 4 & 5\end{array}$

- Product and Process innovations are important to our organization, So we keep up with latest improvements $1 \quad 2 \quad 3 \quad 4 \quad 5$

- Innovation and Entrepreneurship include some failures, and our organization accepts this fact. $\quad \begin{array}{lllll}1 & 2 & 3 & 4 & 5\end{array}$

\section{Radical Innovation}

- We create more completely new products than our competitors

$\begin{array}{lllll}1 & 2 & 3 & 4 & 5\end{array}$

- We introduce more radically new concept and functions in products than our competitors

123245

- We are often the creator of new techniques and procedure skills

$\begin{array}{lllll}1 & 2 & 3 & 4 & 5\end{array}$

- We often introduce completely new products in the new market

$\begin{array}{lllll}1 & 2 & 3 & 4 & 5\end{array}$

- Our Innovations are based on a revolutionary change in technology

$\begin{array}{lllll}1 & 2 & 3 & 4 & 5\end{array}$

\section{Incremental Innovation}

- We create more novel patterns of products than our competitors

$\begin{array}{lllll}1 & 2 & 3 & 4 & 5\end{array}$

- We improve more existing process and products than our competitors

$\begin{array}{lllll}1 & 2 & 3 & 4 & 5\end{array}$

- We exploit existing technologies more deeply than our competitors

$\begin{array}{lllll}1 & 2 & 3 & 4 & 5\end{array}$

- We introduce new products incrementally in the market

$\begin{array}{lllll}1 & 2 & 3 & 4 & 5\end{array}$

- We use Innovation as a minor improvement tool over the technology

$\begin{array}{lllll}1 & 2 & 3 & 4 & 5\end{array}$

Any further information/ suggestions: 